Aksiologiya: Jurnal Pengabdian Kepada Masyarakat

Vol.5, No. 2, Mei 2021 Hal 182 - 190

ISSN 2528-4967 (print) dan ISSN 2548-219X (online)

\title{
Mendorong Keikutsertaan Suami dalam Program Keluarga Berencana Melalui Perbaikan Pemahaman tentang Metode Kontrasepsi
}

\author{
Dedik Sulistiawan', Siti Fatimah ${ }^{2}$, Joharotul Laila Ummu Hana ${ }^{3}$, Ficky \\ Kurniawan Candra ${ }^{4}$, Oetami Riezki Cahyani ${ }^{5}$, Inayah Shafira ${ }^{6}$, Syariatul \\ Dirgantara $^{7}$ \\ Program Studi Kesehatan Masyarakat, Fakultas Kesehatan Masyarakat, \\ Universitas Ahmad Dahlan \\ E-mail: dedik.sulistiawan@ikm.uad.ac.id'1, fatimahcute1999@gmail.com², \\ ummuhana.joha@gmail.com³ , fickykurniawan47@gmail.com4, rcahyaniiitami@ \\ gmail.com ${ }^{5}$, inayah.shafira@yahoo.co.id ${ }^{6}$, dirgantaratara99@gmail.com ${ }^{7}$ \\ Corresponding author: Dedik Sulistiawan ${ }^{1}$
}

\begin{abstract}
ABSTRAK
Partisipasi pria merupakan salah satu masalah yang masih dihadapi dalam program keluarga berencana di beberapa negara termasuk Indonesia. Program keluarga berencana yang berfokus pada kaum perempuan di tengah masyarakat yang menganut sistem patriarki menyebabkan adanya kesan bahwa perempuanlah yang memiliki tanggung jawab dalam hal pengaturan kehamilan. Program pengabdian masyarakat ini bertujuan untuk mendorong keikutsertaan suami dalam program keluarga berencana melalui perbaikan pemahaman tentang metode kontrasepsi. Setelah mengikuti kegiatan ini, diharapkan para suami memiliki wawasan yang luas tentang metode kontrasepsi. Pengabdian kepada masyarakat ini dilakukan terintegrasi melalui kegiatan Pengalaman Belajar Lapangan (PBL) Fakultas Kesehatan Masyarakat Universitas Ahmad Dahlan tahun 2020 di Dusun Modalan, Banguntapan, Bantul pada tanggal 19 sampai dengan 20 Februari 2020. Pendekatan yang dilakukan adalah melalui musyawarah masyarakat desa sebagai bentuk community engagement dan edukasi tentang mitos dan fakta seputar metode kontrasepsi dan keluarga berencana. Program pengabdian kepada masyarakat ini terbukti secara signifikan mampu meningkatkan pengetahuan pria dalam isu keluarga berencana (Mean difference $=27,40 ; 95 \% \mathrm{CI}=12,64-42,17$; $p$-value $=0,001$ ). Keterlibatan masyarakat mulai dari proses penentuan prioritas masalah menjadikan intervensi yang dilakukan benar-benar merupakan kebutuhan masyarakat. Hal ini secara tidak langsung menyebabkan sasaran berpartisipasi secara aktif selama kegiatan berlangsung, sehingga pengetahuannya tentang keluarga berencana meningkat.
\end{abstract}

Kata Kunci: kontrasepsi; keluarga berencana; partisipasi suami.

\section{Encouraging Male Participation in the Family Planning Program Through Improving Understanding of the Contraception Methods}

\begin{abstract}
Male involvement is one of the challenges of the family planning program in many countries, including Indonesia. The family planning program, which focuses on women in a society that adopts a patriarchal structure, causes the perception that women have responsibilities in regulating pregnancy. This community engagement initiative was developed to promote husbands'involvement in family planning programs through an increased understanding of contraceptive methods. After engaging in this activity, it is hoped that the husbands will have broad insights into contraception
\end{abstract}


Dedik Sulistiawan, Siti Fatimah, Joharotul Laila Ummu Hana, Ficky Kurniawan Candra, Oetami Riezki Cahyani, Inayah Shafira, Syariatul Dirgantara/ Aksiologiya: Jurnal Pengabdian Kepada Masyarakat. Vol.5, No. 2, Mei 2021 Hal 182 - 190

methods. This community development was carried out through the Field Study Experience (PBL) of Faculty of Public Health Universitas Ahmad Dahlan in Dusun Modalan, Banguntapan, Bantul, from 19 to 20 February 2020. Through village group meetings, the approach taken was a medium of community involvement and education about the rumors and truth about contraception and family planning practices. This community service initiative has been shown to substantially increase male knowledge on family planning issues (mean difference $=27.40 ; 95 \% C I=12.64-42.17$; $p$-value $=$ 0.001). Community involvement in the process of determining priority problems makes interventions become a community need. This indirectly causes the target to engage actively during the activity, consequently increasing their understanding of family planning.

Keywords: contraception; family planning; male involvement.

\section{PENDAHULUAN}

Program Keluarga Berencana (KB) merupakan salah satu cara yang digunakan pemerintah untuk menekan laju pertumbuhan penduduk serta meningkatkan kesehatan ibu dan anak. Hal ini seiring dengan semakin meningkatnya jumlah penduduk Indonesia serta tingginya angka kematian ibu dan kebutuhan akan kesehatan reproduksi, Menurut World Population Data Sheet 2013, Indonesia merupakan negara kelima di dunia dengan estimasi jumlah penduduk terbanyak, yaitu 249 juta. Di antara negara ASEAN, Indonesia dengan luas wilayah terbesar tetap menjadi negara dengan penduduk terbanyak, jauh di atas negara anggota yang lain (Kementerian Kesehatan RI, 2014).

Hasil Survei Demografi dan Kesehatan Indonesia (SDKI) 2017 menunjukkan bahwa angka kesuburan total (total fertility rate/ TFR) adalah 2,4 anak, yang berarti bahwa seorang wanita di Indonesia melahirkan ratarata 2,4 anak selama hidupnya. Tren ini telah menurun dibandingkan dengan hasil SDKI dari 2002-2003 ke SDKI 2012. Meskipun angka kelahiran untuk wanita berusia 2024 tahun telah menurun dari 138 kelahiran per 1.000 wanita di SDKI 2012 menjadi 111 di SDKI 2012, namun terjadi peningkatan pada wanita berusia $30-34$ tahun, dari 103 kelahiran per 1.000 wanita di SDKI 2012 menjadi113 di SDKI 2017 ( BPS, BKKBN, Kementerian Kesehatan, dan ICF International, 2018)

Meningkatnya TFR merupakan dampak langsung dari tingginya proporsi kebutuhan ber-KB yang tidak terpenuhi (unmet need) pada wanita usia subur. Unmet need merupakan salah satu tantangan yang masih dihadapi oleh beberapa negara berkembang, termasuk Indonesia. Unmet need selalu dikaitkan dengan angka kematian ibu akibat kejadian kehamilan yang tidak diinginkan (unwanted pregnancy)(Lumbantobing et al., 2019). Hal ini disebabkan karena kehamilan tidak diinginkan kebanyakan berakhir dengan aborsi yang tidak aman (unsafe abortion) (Darroch et al., 2011; Mohammed et al., 2016). Persentase unmet need di beberapa daerah di Daerah Istimewa Yogyakarta meningkat setiap tahun. Pada tahun 2018, kabupaten dengan persentase unmet need terendah adalah KabupatenGunungKidul(8,80persen) dan yang tertinggi adalah Yogyakarta $(15,14$ persen). Sementara Kabupaten 
Dedik Sulistiawan, Siti Fatimah, Joharotul Laila Ummu Hana, Ficky Kurniawan Candra, Oetami Riezki Cahyani, Inayah Shafira, Syariatul Dirgantara/ Aksiologiya: Jurnal Pengabdian Kepada Masyarakat. Vol.5, No. 2, Mei 2021 Hal 182 - 190

Bantul merupakan kabupaten dengan proporsi unmet need tertinggi kedua setelah Kota Yogyakarta, yaitu 10,55 persen (Pemerintah Daerah Istimewa Yogyakarta, 2019).

Pemerintah melalui Badan Kependudukan dan Keluarga Berencana (BKKBN) terus berupaya untuk meningkatkan partisipasi masyarakat dalam program KB. Sesuai dengan tugas pokok dan fungsinya, BKKBN memilih tanggung jawab dalam menyelenggarakan komunikasi, informasi dan edukasi di bidang Kependudukan dan Keluarga Berencana (KKB) kepada seluruh lapisan masyarakat, khususnya Pasangan Usia Subur (PUS) (BKKBN, 2020). Tidak hanya untuk perempuan, pemerintah juga berupaya melibatkan laki-laki dalam program KB.

Sejak tahun 1999, perhatian terhadap keikutsertaan kaum lakilaki dalam program $\mathrm{KB}$ telah mulai digagas dan. Sebelumnya, program KB hanya berfokus pada kaum perempuan sehingga terkesan bahwa perempuanlah yang memiliki tanggung jawab dalam hal pengaturan kehamilan. Pendekatanyangdilakukan antara lain menempatkan laki-laki agar dapat memperoleh informasi tentang KB yang benar, mendukung pasangan menggunakanalatkontrasepsitertentu, serta membantu mempertahankan dan meningkatkan kesehatan ibu hamil, merencanakan persalinan aman oleh tenaga medis (Sutinah, 2017).

Meskipun demikian, upaya untuk melibatkan laki-laki dalam program KB menemui jalan yang tidak mudah. Pada tahun 2019, dari 37.885 orang peserta KB baru di Daerah Istimewa Yogyakarta, hanya 7\% di antaranya adalah laki-laki. Meskipun demikian, angka ini meningkat dari tahun sebelumnya yang hanya 6\% (Bappeda DIY, 2020). Hal ini mengindikasikan bahwa sebenarnyalaki-lakimerupakan kelompok yang cukup potensial untuk didorong menggunakan kontrasepsi.

Dalam beberapa studi, lakilaki memiliki pengetahuan yang baik tentang metode kontrasepsi, namun hanya sedikit sekali yang mau menerapkan metode kontrasepsi tertentu (Joshi, 2015; Kabagenyi et al., 2014) khususnya di negara berkembang, tak terkecuali Indonesia (Haryanto, 2018). Rendahnya keterlibatan suami dalam program KB disebabkanolehbeberapahalyaituefek samping yang dirasakan dari metode kontrasepsi wanita yang mengganggu aktivitas seksual, terbatasnya pilihan kontrasepsi pria termasuk ketakutan dan kekhawatiran terkait vasektomi, persepsi bahwa kesehatan reproduksi adalah domain wanita, dan perbedaan preferensi fertilitas (Dral et al., 2018; Kabagenyi et al., 2014). Selain itu, rendahnya tingkat pendidikan dan penghasilan, jenis pekerjaan di sektor informal, lemahnya kebijakan dan program $\mathrm{KB}$, serta praktik budaya patriarki menyebabkan rendahnya partisipasi pria dalam program KB (Joshi, 2015). Keterpaparan informasi tentang KB dari media masa dan petugas kesehatan juga merupakan faktor yang mendorong partisipasi pria dalam program KB (Bishwajit et al., 2017).

Permasalahan tersebut, 
Dedik Sulistiawan, Siti Fatimah, Joharotul Laila Ummu Hana, Ficky Kurniawan Candra, Oetami Riezki Cahyani, Inayah Shafira, Syariatul Dirgantara/ Aksiologiya: Jurnal Pengabdian Kepada Masyarakat. Vol.5, No. 2, Mei 2021 Hal 182 - 190

menjadikan penulis melakukan kegiatan pengabdian kepada masyarakat dengan topik "Mendorong Keikutsertaan Suami dalam Program Keluarga Berencana Melalui PerbaikanPemahamantentang Metode Kontrasepsi di Dusun Modalan, Banguntapan, Bantul”. Harapannya, setelah mengikuti kegiatan ini, para suami memiliki wawasan yang luas tentang metode kontrasepsi sehingga partisipasinya dalam program $\mathrm{KB}$ meningkat.

\section{METODE PENELITIAN}

Tempat dan Waktu. Kegiatan pengabdian kepada masyarakat ini dilakukan dalam waktu 2 hari, yaitu mulai tanggal 19 sampai dengan 20 Februari 2020 di Balai Pertemuan Dusun Modalan, Kecamatan Banguntapan, Kabupaten Bantul, Daerah Istimewa Yogyakarta.

Khalayak Sasaran. Kegiatan pengabdian kepada masyarakat hari pertama melibatkan 20 orang ibu-ibu dasawisma dalam rangka brainstorming (musyawarah masyarakat dusun) dan menentukan prioritas masalah kesehatan yang akan diintervensi. Kegiatan hari kedua melibatkan 19 bapak-bapak di RT. 5 sampai 9 Dusun Modalan, Kecamatan Banguntapan, Kabupaten Bantul, Daerah Istimewa Yogyakarta sebagai sasaran intervensi program kesehatan.

Metode Pengabdian. Pengabdian kepada masyarakat ini dilakukan terintegrasi melalui kegiatan Pengalaman Belajar Lapangan (PBL) Fakultas Kesehatan Masyarakat
Universitas Ahmad Dahlan tahun 2020. Sebelum dilakukan kegiatan pengabdian, terlebih dahulu dilakukan asesmen awal (baseline assessment) menggunakan teknik survei cepat berbasis rumah tangga. Hari pertama merupakan kegiatan Musyawarah Masyarakat Dusun (MMD). Kegiatan ini merupakan pertemuan dalam rangka konfirmasi hasil temuan selama baseline assessment penggunaan kontrasepsi di Dusun Modalan, Kecamatan Banguntapan, Kabupaten Bantul. Pertemuan ini merupakan sarana community engagement sehingga program/ intervensi yang akan dilakukan benar-benar merupakan kebutuhan masyarakat. Teknik yang digunakan dalam memprioritaskan masalah kesehatan adalah metode Urgency, Seriousness, and Growth (USG). Pada hari kedua pengabdian masyarakat dilakukan edukasi penggunaan beberapa jenis alat/ metode kontrasepsi serta mitos dan faktanya. Inovasi edukasi tentang $\mathrm{KB}$ dilakukan dengan menggunakan permainan "mitos atau fakta". Kegiatan ini dilakukan selama 200 menit.

\section{Indikator Keberhasilan.}

Indikator keberhasilan program pengabdian kepada masyarakat ini adalah meningkatnya pengetahuan para suami terkait metode kontrasepsi setelah dilakukan edukasi.

Metode Evaluasi. Sebelum intervensi dilakukan, peserta diberikan pre-test, serta post-test setelah intervensi dilakukan sebagai bentuk evaluasi atas ketercapaian indikator keberhasilan. Uji t sampel 
Dedik Sulistiawan, Siti Fatimah, Joharotul Laila Ummu Hana, Ficky Kurniawan Candra, Oetami Riezki Cahyani, Inayah Shafira, Syariatul Dirgantara/ Aksiologiya: Jurnal Pengabdian Kepada Masyarakat. Vol.5, No. 2, Mei 2021 Hal 182 - 190

berpasangan (paired t-test) digunakan untuk menguji kebermaknaan perubahan tingkat pengetahuan antara sebelum dan sesudah pemberian intervensi.

\section{HASIL DAN PEMBAHASAN}

Kegiatan pengabdian kepada masyarakat hari pertama dihadiri oleh ibu-ibu dasawisma RT. 5-9 Dusun Modalan, Kepala Dusun Modalan, dan kader kesehatan Dusun Modalan sebanyak 20 orang. Kegiatan ini diselenggarakan dalam rangka konfirmasi hasil temuan selama baseline assessment penggunaan kontrasepsi. Setelah memaparkan hasil baseline assessment, dilakukan dikusi mengenai prioritas masalah dan solusi atas temuan yang dipaparkan. oleh 19 orang bapak-bapak yang tinggal di RT. 5-9 Dusun Modalan, Kecamatan Banguntapan, Kabupaten Bantul. Berdasarkan musyawarah dengan masyarakat Dusun Modalan, disepakati bahwa rendahnya pengetahuan masyarakat tentang metode kontrasepsi dan rendahnya partisipasi suami dalam program KB merupakan masalah yang perlu mendapatkan penanganan segera. Oleh karena itu, intervensi yang disepakati yaitu melakukan edukasi kepada para bapak di Dusun Modalan Desa Banguntapan Kabupaten Bantul dengan harapan dapat meningkatkan pemahaman jenis dan metode kontrasepsi modern. Selain itu, melalui intervensi ini diharapkan para bapak juga memiliki sikap positif

Tabel 1. Skoring Masalah Menggunakan Metode Urgency, Seriousness, and Growth (USG)

\begin{tabular}{|c|c|c|c|c|c|c|c|c|c|c|c|c|}
\hline \multirow{2}{*}{ No } & \multirow{2}{*}{ Kriteria } & \multirow{2}{*}{ Bobot } & \multicolumn{5}{|c|}{ Skor Masalah } & \multicolumn{5}{|c|}{ Skor Total } \\
\hline & & & $\mathbf{A}$ & B & $\mathrm{C}$ & D & $\mathbf{E}$ & $\mathbf{A}$ & B & $\mathrm{C}$ & D & $\mathbf{E}$ \\
\hline 1 & Urgency & 3 & 6 & 8 & 4 & 5 & 8 & 18 & 24 & 12 & 15 & 24 \\
\hline 2 & Seriousness & 4 & 7 & 8 & 4 & 6 & 8 & 28 & 32 & 16 & 24 & 32 \\
\hline 3 & Growth & 3 & 5 & 6 & 4 & 4 & 7 & 15 & 18 & 12 & 12 & 21 \\
\hline \multicolumn{8}{|c|}{ Total Skor } & 61 & 74 & 40 & 51 & 77 \\
\hline
\end{tabular}

Keterangan:

A: Keikutsertaan KB

B: Dukungan Suami dalam KB

C: Dukungan Keluarga dalam KB

D: Dukungan Kader dalam KB

E: Pengetahuan Kontrasepsi

Pada hari kedua, dilakukan kegiatan intervensi yang dihadiri

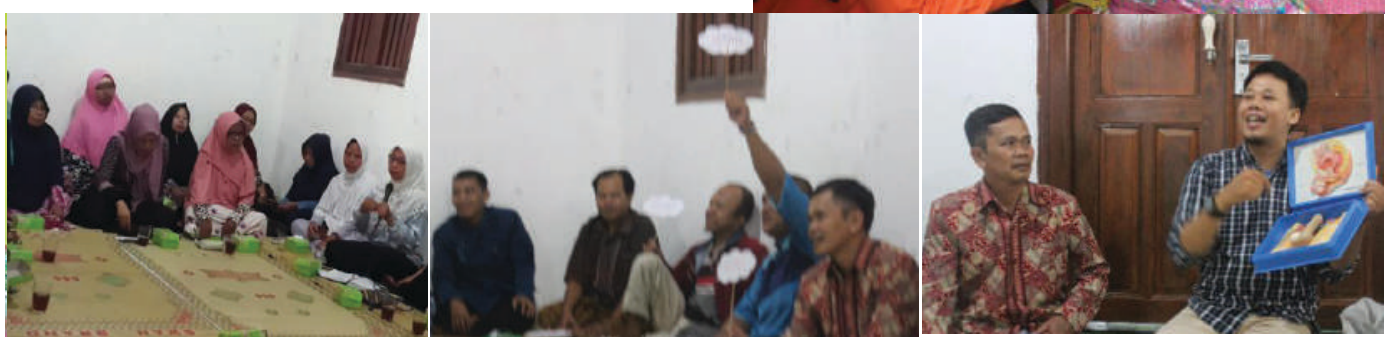

Gambar 1. Atas : Proses Asesmen Awal, Bawah Kiri ke kanan: Musyawarah Masyarakat Dusun, Edukasi Mitos vs. Fakta Kontrasepsi, dan Penjelasan Metode Kontrasepsi Pria 
Dedik Sulistiawan, Siti Fatimah, Joharotul Laila Ummu Hana, Ficky Kurniawan Candra, Oetami Riezki Cahyani, Inayah Shafira, Syariatul Dirgantara/ Aksiologiya: Jurnal Pengabdian Kepada Masyarakat. Vol.5, No. 2, Mei 2021 Hal 182 - 190

terkait metode kontrasepsi sehingga mendukung pelaksanaan program KB

Peserta pelatihan sangat antusias dalam mengikuti kegiatan pelatihan ini dibuktikan dengan banyaknya pertanyaan yang disampaikan kepada narasumber. Selain itu, pada melakukan permainan "mitos atau fakta", peserta menyampaikan beberapa pendapatnya seputar penggunaan metode kontrasepsi. Dari sebanyak 19 orang peserta, sebanyak 16 orang mengikuti kegiatan dari awal sampai akhir serta mengikuti evaluasi (pre dan posttest).

Tabel 2 memberikan informasi bahwa rata-rata perubahan skor pengetahuan tentang metode kontrasepsi antara sebelum dan sesudah mendapatkan edukasi adalah sekitar 27,4 poin. Menggunakan uji $\mathrm{t}$ sampel berpasangan pada tingkat kemaknaan 5\%, intervensi yang diberikan terbukti secara signifikan mampu meningkatkan pengetahuan partisipan. Dengan demikian, edukasi menggunakan pendekatan bermain "mitos atau fakta" cukup efektif dalam meningkatkan pengetahuan para suami/ laki-laki tentang metode kontrasepsi. strategi antara lain pendidikan atau konseling berbasis pasangan, pengambilan keputusan bersama mengenai penggunaan kontrasepsi, memobilisasi pria sebagai mitra untuk menciptakan kesadaran dan kemauan untuk mengadopsimetodekontrasepsi, dan mengizinkan serta mendukung pasangan untuk menggunakan metode kontrasepsimodern(Comrie-Thomson et al., 2019; Gebrie et al., 2017; Koren et al., 2017). Lebih lanjut, sebuah studi merekomendasikan tiga macam pendekatan, yaitu melibatkan pria sebagai klien secara eksklusif, diikuti dengan melibatkan pria sebagai mitra, dan melibatkan pria sebagai agen perubahan (Adamou et al., 2019).

Sebagai klien, upaya yang dapat dilakukan adalah mendorong secara aktif pria untuk menjadi akseptor KB. Sedangkansebagaimitra,priadidorong agar mau mendukung penggunaan kontrasepsi modern untuk diri mereka sendiri atau pasangan mereka. Selain itu, pria juga didorong untuk mau berbagi dalam pengambilan keputusan masalah kesehatan reproduksi dengan pasangannya. Adapun sebagai agen perubahan, pria perlu mendapatkan pelatihan tentang kesetaraan gender

Tabel 2. Perubahan Pengetahuan Sebelum dan Sesudah Intervensi

\begin{tabular}{cccccc}
\hline Kelompok & n & Mean \pm SD & $\begin{array}{c}\text { Mean } \\
\text { Difference }\end{array}$ & $\mathbf{9 5 \%}$ CI & p-value \\
\hline Sebelum Intervensi & 16 & $42,52 \pm 16,74$ & & & \\
Sesudah Intervensi & 16 & $69,93 \pm 18,87$ & 27,40 & $12,64-42,17$ & $0,001^{*}$ \\
\hline
\end{tabular}

*Paired $t$-test, signifikan pada $\mathrm{p}<0,05$

Upaya untuk melibatkan suami dalam program $\mathrm{KB}$ telah dilakukan di beberapa negara melalui beberapa sehingga mereka memiliki sikap yang positif terkait norma gender (Adamou et al., 2019). 
Pengetahuan tentang kontrasepsi bagaimanapun juga memegang peran sentral dalam hal keterlibatan pria dalam keluarga berencana sebagaimana hasil dari beberapa studi terdahulu (Ghanotakis et al., 2017; Kriel et al., 2019; Mahmood et al., 2016). Kurangnya informasi dan pemahaman di kalangan pria dapat mengakibatkan asumsi yang salah tentang efek samping dan sikap negatif terhadap metode kontrasepsi. Selain itu, hal ini dapat mendorong kesalahpahaman antara fakta dan mitos tentang program KB (Kriel et al., 2019). Intervensi isu gender berbasis masyarakat yang terdiri atas pendidikan bagi pria dalam rangka membangun pengetahuan tentang KB terbukti mampu meningkatkan akses pria dalam penggunaan layanan kesehatan, khususnya KB (Ghanotakis et al., 2017). Selain itu, pelibatan pria secara aktif dan terus menerus menurut studi terdahulu terbukti mampu meningkatkan partisipasi dalam $\mathrm{KB}$ dan secara umum safe motherhood. Strategi yang dilakukan antara lain dengan membentuk motivator KB pria, memilih waktu yang tepat misalnya akhir pekan dalam penyelenggaraan kegiatan KB yang melibatkan pria, serta mendesain tempat kerja yang mengkampanyekan keterlibatan pria dalam KB dan upaya safe motherhood (Ouma et al., 2018)

\section{SIMPULAN}

Program pengabdian kepada masyarakat dengan metode edukasi mitos dan fakta tentang kontrasepsi terbukti secara signifikan mampu meningkatkan pengetahuan pria dalam isu keluarga berencana. Selain itu, keterlibatan masyarakat dalam dari proses penentuan prioritas masalah menjadikan intervensi yang dilakukan benar-benar merupakan kebutuhan masyarakat. Hal ini disebabkan karena rasa memiliki (sense of ownership) merupakan salah satu kunci keberhasilan kegiatan yang melibatkan masyarakat (community development).

\section{DAFTAR PUSTAKA}

Adamou, B. M., Iskarpatyoti, B. S., Agala, C. B., \& Mejia, C. (2019). Exploring gaps in monitoring and evaluation of male engagement in family planning. Gates Open Research, 3, 1-18. https://doi.org/10.12688/ gatesopenres.12927.1

Bappeda DIY. (2020). Jumlah peserta KB Baru Daerah Istimewa Yogyakarta. Aplikasi Dataku. http://bappeda.jogjaprov.go.id/ dataku/data_dasar/cetak/373jumlah-peserta-kb-baru

Bishwajit, G., Tang, S., Yaya, S., Ide, S., Fu, H., Wang, M., He, Z., Da, F., \& Feng, Z. (2017). Factors associated with male involvement in reproductive care in Bangladesh. BMC Public Health, 17(1), 1-8. https:// doi.org/10.1186/s12889-016$3915-\mathrm{y}$

BKKBN. (2020). Tugas Pokok dan Fungsi BKKBN. https://www. bkkbn.go.id/pages/tugas pokok-dan-fungsi

Comrie-Thomson, L., Mavhu, W., Makungu, C., Nahar, Q., Khan, R., Davis, J., Stillo, E., Hamdani, S., Luchters, S., \& Vaughan, C. (2019). Male involvement interventions and improved couples' emotional 
Dedik Sulistiawan, Siti Fatimah, Joharotul Laila Ummu Hana, Ficky Kurniawan Candra, Oetami Riezki Cahyani, Inayah Shafira, Syariatul Dirgantara/ Aksiologiya: Jurnal Pengabdian Kepada Masyarakat. Vol.5, No. 2, Mei 2021 Hal 182 - 190

relationships in Tanzania and Zimbabwe: 'When we are walking together, I feel happy.' Culture, Health and Sexuality, O(0), 1-18. https://doi.org/10.10 80/13691058.2019.1630564

Darroch, J. E., Sedgh, G., \& Ball, H. (2011). Contraceptive Technologies: Responding to Women' s Needs. Guttmacher Institute, April, 1-51.

Dral, A. A., Tolani, M. R., Smet, E., Luijn, A. Van, Van Luijn, A., \& Luijn, A. Van. (2018). Factors Influencing Male Involvement in Family Planning in Ntchisi District, Malawi A Qualitative Study. African Journal of Reproductive Health, 22(December), 35-43. https:// doi.org/10.29063/ajrh2018/ v22i4. 4

Gebrie, S.A.,Abraha, Y.G., Garoma,D. A., Deribe, F. M., Tefera, M. H., \& Morankar, S. (2017). Impact of male partner involvement on modern contraceptive use among married or partnered women in developing countries: a protocol for systematic review. JBI Database of Systematic Reviews and Implementation Reports, 15(12), 2837-2841. https://doi. org/10.11124/JBISRIR-2016003106

Ghanotakis, E., Hoke, T., Wilcher, R., Field, S., Mercer, S., Bobrow, E. A., Namubiru, M., Katirayi, L., \& Mandera, I. (2017). Evaluation of a male engagement intervention to transform gender norms and improve family planning and HIV service uptake in Kabale, Uganda. Global Public Health, 12(10), 1297-1314. https://doi. org/10.1080/17441692.2016.11 68863

Haryanto, S. (2018). Engaging Men: Results of the MenCare+ Gender Justice Program in Indonesia.
Journal of Men's Studies, 26(1), 40-55. https://doi. $\mathrm{rg} / 10.1177 / 1060826517711158$

Joshi, L. R. (2015). Male Participation in Family Planning: Human Behaviour Perspective. Journal of Nepal Health Research Council, 13(31), 188-195.

Kabagenyi, A., Jennings, L., Reid, A., Nalwadda, G., Ntozi, J., \& Atuyambe, L. (2014). Barriers to male involvement in contraceptive uptake and reproductive health services: a qualitative study of men and women' $s$ perceptions in two rural districts in Uganda Research suggests that male involvement can increase uptake and continuation of $\mathrm{f}$. Reproductive Health, 11(21), $1-9$.

Kementerian Kesehatan RI. (2014). Situasi dan Analisis Keluarga Berencana. In Kementerian Kesehatan Republik Indonesia (p. 2). Pusat Data dan Informasi Kementerian Kesehatan Republik Indonesia.

Koren, A., Giannetti, M., Hynes, R., \& Favre, M. (2017). Integrating Male Reproductive Health Services: One University Clinic's Story. Journal of Sex and Marital Therapy, 43(1), 15-23. https://doi.org/10.1080/ 0092623X.2015.1113594

Kriel, Y., Milford, C., Cordero, J., Suleman, F., Beksinska, M., Steyn, P., \& Smit, J. A. (2019). Male partner influence on family planning and contraceptive use: Perspectives from community members and healthcare providers in KwaZulu-Natal, South Africa. Reproductive Health, 16(1). https://doi.org/10.1186/s12978019-0749-y

Lumbantobing, D., Bemmelen, S. Van, Pratiwi, A. M., \& Dhewy, A. 
(2019). Community Knowledge and Behavior Towards Unwanted Pregnancy in Eight Provinces of Sumatra: Between Religious, Customary and State Norms. Jurnal Perempuan, 24(3), 275-288. https://doi. org/10.18860/egalita.v0i0.2000

Mahmood, H., Khan, Z., \& Masood, S. (2016). Effects of male literacy on family size: A cross sectional study conducted in Chakwal city. Journal of the Pakistan Medical Association, 66(4), 399-403.

Mohammed, F., Musa, A., \& Amano, A. (2016). Prevalence and determinants of unintended pregnancy among pregnant woman attending ANC at Gelemso General Hospital, Oromiya Region, East Ethiopia: A facility based cross-sectional study. BMC Women's Health, 16(1), 10-16. https://doi. org/10.1186/s12905-0160335-1

Ouma, G., Karanja, S., \& Udu, D. (2018). Factors Influencing Male Involvementin Safe Motherhood Among Communities in Kwale And Kilifi in Coastal Kenya. In Global Journal of Health Sciences (Vol. 3, Issue 1).

Pemerintah Daerah Istimewa Yogyakarta. (2019).

Perkembangan Unmet Need KB di DIY Menurut Kabupaten Kota. Aplikasi Dataku DIY. http://bappeda.jogjaprov.go.id/ dataku/data_dasar/index/646perkembang\%250Aan-unmetneed-kb-di-diy-menurutkabupaten-kota\% $250 \mathrm{~A}$

Statistics Indonesia (Badan Pusat Statistik-BPS) National Population and Family Planning Board (BKKBN) and Kementerian Kesehatan (Kemenkes-MOH) and ICF International. (2018). Survei
Demografi dan Kesehatan Indonesia 2017. BPS, BKKBN, Kemenkes, and ICF International.

Sutinah, S. (2017). Partisipasi lakilaki dalam program Keluarga Berencana di era masyarakat postmodern. Masyarakat, Kebudayaan Dan Politik, 30(3), 290. https://doi.org/10.20473/ mkp.v30i32017.290-299 